\title{
Solution to the Problem of Lanslide-Prone Territories Using Geodesic Methods
}

\author{
Ibragimova E.I. \\ Grozny State Oil Technical University \\ named M.D. Millionshikova \\ Grozny, Russia \\ lina.leams@mail.ru \\ Mishiyeva A.T. \\ Grozny State Oil Technical University \\ named M.D. Millionshikova \\ Grozny, Russia \\ zuba-866@yandex.ru \\ Murtazova Kh.M.-S. \\ Grozny State Oil Technical University \\ named M.D. Millionshikova \\ Grozny, Russia \\ fu.ggni@mail.ru
}

\begin{abstract}
The article presents the observations of the landslide-prone northern slope of the Sunzhenskiy range to the south of the village of Podgorny in the Staropromyslovskiy district, Grozny using the kinoteodolite method in dynamics. According to the observations of the slope, it was possible to predict the behavior of the landslide and take measures to protect the population living in dangerous areas of the foothills. Methods for studying the stress-strain state of rockslides are considered. Many options for constructing maps of hazardous areas are described. The advantages and disadvantages of each method are given.
\end{abstract}

Keywords-lanslide-prone slope, kinoteodolite method, geophysical observations, metrological parametres, seismic effects, benchmarks, surface capture of the earth's crust, GIS-technologies, observation techniques, shooting, maps

\section{INTRODUCTION}

Active urbanization processes lead to several global and local geoecological problems caused by the spread and activation of dangerous natural and techno-natural processes. The consequences of such processes can lead to catastrophic destruction of buildings, as well as to the death of people. Therefore, one of the main problems of modern geoecology is to monitor the state and stability of densely populated areas, while studying the processes of penetration of the natural and technogenic environment into seismic areas, to which the Chechen Republic belongs, is of crucial importance. In such conditions, the forecasting of landslides, their impact on residential areas and industrial facilities takes the first place.

\author{
Gayrabekov I.G. \\ Grozny State Oil Technical University \\ named M.D. Millionshikova, \\ Kh. Ibragimov Complex Institute of the Russian Academy \\ Sciences, Grozny, Russia \\ ibragim.ggni@mail.ru \\ Yalmayeva M.A \\ Grozny State Oil Technical University \\ named M.D. Millionshikova \\ Grozny, Russia \\ makka1979@ya.ru \\ Gayrabekova A.I. \\ Grozny State Oil Technical University \\ named M.D. Millionshikova \\ Grozny, Russia \\ ibragim.ggni@mail.ru
}

Landslide processes form an ecological framework. Observations on landslides indicate the laws of propagation, as well as the composition and structure of the framework Monitoring is designed to control and prevent the unstable development of territories.

The geodesic method of landslide control is based on the use of modern electronic and optical devices, ground laser scanners, which can become the technical basis of the monitoring system automatically.

The article describes the experience of using kinoteodolite method for monitoring landslide and changes in the dynamics. Along with meteorological and geophysical observations, the use of kinoteodolite allows to know in advance when a landslide begins to be active and carry out a complex of evacuation activities of the population from the danger zone timely until the phase of catastrophic shifts begins.

In 2016-2017, in the framework of the work "Development and experience of the automated system segment for monitoring hazardous natural (inclined) processes", the sphere of the automated system for monitoring hazardous inclined processes was created.

\section{METHODS AND MATERIALS}

In the article various methods of regional zoning of territories by the risk of landslide are analyzed and techniques based on modern GIS technologies are described. Various 
methods of studying the terrain are presented, as well as their laboriousness and dependence on various external conditions.

The article presents the study results of the landslide-prone area above the village Podgorny, Staropromyslovskiy district, Grozny. The landslide process in this area belongs to the "rhythmic" class, when active periods alternate with periods of attenuation of the motor process activity.

On the site, kinoteodolite monitoring was carried out. This method provides general observation of the processes occurring on the surface of the landslide-prone slope. All observations were reproduced on a computer screen by transferring images from video cameras installed on a slope.

\section{RESULTS}

Observations on the slope movements include determining the vertical and horizontal displacements of points on the surface and in the depth of the slope with a given periodicity, as well as changes in the crack opening revealed during a landslide survey, and the inclination of individual sections $[7,8]$. The geodesic method of landslide control is based on the use of modern electronic and optical devices, ground laser scanners, which can become the technical basis of the monitoring system automatically.

It is known that a landslide is a physical-geological phenomenon. It is a movement of earth masses down the slope under the influence of gravity. There are different forms of landslide processes: from subtle plastic movements to catastrophic landslides. Landslides on the slopes are caused by groundwater and surface water, which change the cohesive forces in the soil and bring them out of balance. Their appearance often is associated with the emergence of aquifers on the surface, wetting slopes and causing eluvial-diluvial masses to slip on bedrock [9]. When a landslide collapses on a slope, a semicircular notch called a landslide circus is often formed.

Landslides should be studied for assessment and prediction of their effects on nearby objects. These observations are performed by various geodetic methods. Depending on the type, activity, direction and speed of movement of a landslide, these methods are divided into four groups:

- axial (one-dimensional), when the displacements of the points fixed on the landslide are defined towards a given line or axis;

- $\quad$ planned (two-dimensional), when the displacement of landslide points is observed by two coordinates in the horizontal plane;

- $\quad$ spatial (three-dimensional), when they find the total displacement of points in space by three coordinates.

To determine the spatial displacement of landslide points phototopographical survey, laser scanning and satellite receivers are used.

In areas with limited satellite visibility, for which it is impossible to use GPS / GLONASS equipment, shooting with electronic total stations is used.
Shifting of landslide points are calculated towards signs located outside the landslide area. The number of signs is determined from a qualitative measurement scheme and all the characteristics of the process and the size of the area. Landslide observations are made at least once a year. Their periodicity is depending on fluctuations of the landslide velocity [10].

Geodesic methods provide global information about the nature of a deformable landslide, while non-geodetic methods provide local information, possibly comparable to the results of some other independent measurements. As noted in [3], landslide detection systems using wireless sensors allow detecting slight soil displacements or instability of terrain slopes, caused, for example, by wetting dielectrics, pore pressure, and other factors. In general, as noted in [3], landslides lead to significant changes in the natural environment. For this reason, non-geodetic methods of monitoring can provide significant assistance in the study and landslides prediction.

To determine the spatial displacement of landslide points, various methods of geodesic surveys are used: tacheometric or theodolite survey, aerophototopography, orbital survey, position determination, surface laser scanner, etc. Some of them are presented below:

\section{1) Tacheometric survey}

This method is operative, but if a survey of volumetric territories is carried out, then this process will be laborious, and the duration of all works will increase significantly. The advantage of this method is that it practically does not depend on weather and seasonal conditions. But still this method is popular when solving problems in small areas.

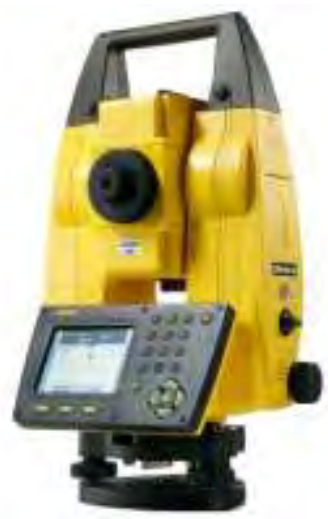

Fig. 1. Total Station Theodolite.

\section{2) Aerophototopography}

This method is time consuming and requires ground work, which creates some difficulties. The results of the shooting depend on the time of year, day, and weather conditions. The disadvantage of this survey is complicated getting information in the woodlands.

Fig. 2. Example of aerophototopography

3) Orbital survey 
To survey large areas, it will be necessary to conduct many different field measurements, and therefore work in large areas will take a lot of time. Of course, this method depends little on weather conditions, time of year and day plays an important role, but still when working on built-up areas or in a wooded area, the possibilities of shooting will be somewhat limited due to poor visibility of satellites and surfaces capable of reflecting the signal.

\section{4) Position determination}

It is a fast method, but there is a waste of time for detailed processing of all the images taken. And to obtain digital terrain models control points are needed too. There are almost no limitations on the shooting conditions, so the method is ideal for studying, observing and researching landslide slopes.

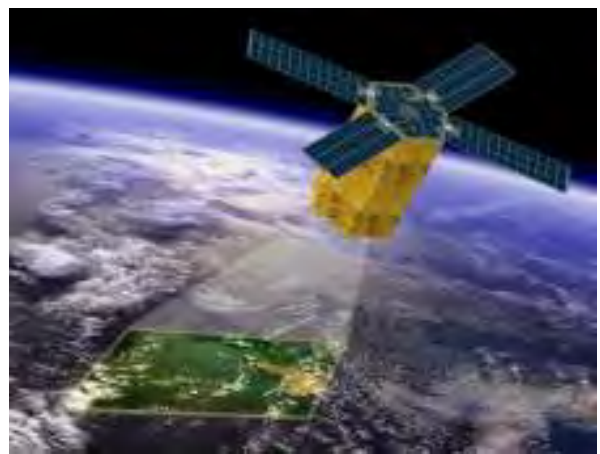

Fig. 3. Position determination

\section{5) Surface laser scanner}

There are few restrictions on shooting conditions, so the method is excellent for monitoring slopes where there is a likelihood of landslides.

\section{6) Airborne laser scanning and aerial imaginary}

If this method is compared with aerial imaginary, it becomes clear that creating a digital terrain model is much easier, and the number of all field work is also reduced. If there are any reflective surfaces in the area of the survey, then there is a probability of signal distortion. Also, in winter, the relief mapping is complicated. Shooting above the limits of the spread of clouds is impossible. The advantages of this method are short time of implementation, the presence of any vegetation which does not interfere with the process. In addition, the fact that several methods are combined in this method increases the information content.

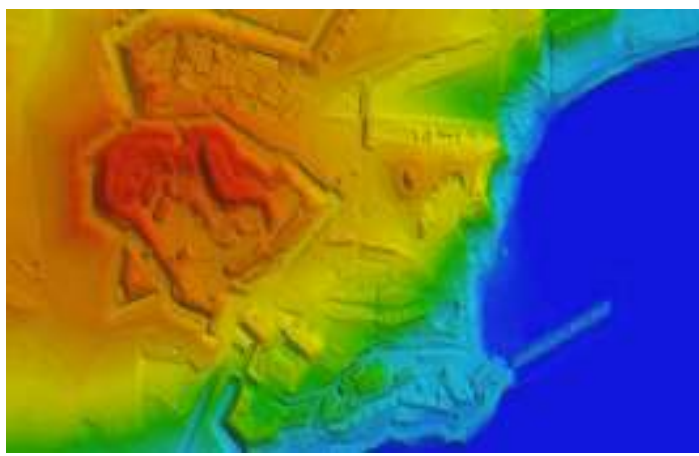

Fig. 4. Area taken by laser scanning.
From all the above, we can conclude that there are several geodetic methods for studying landslide-prone areas. All of them make it possible to create realistic and informative relief models that help to regionally zone the territories by the degree of danger of landslides.

But there are other ways of study too. For example, the method of geodynamic potential is the calculation of the possibility of the landslide process occurrence within the boundaries of the observed area. The procedure for calculating landslide potential and the creation of a predicted map occur in several stages.

1. At the beginning a landslide deformation map is being constructed.

2. The separation of factors into groups. The number of groups is formed considering the extremes produced on the oblique line. When the final is rounded with 1 maximum, then the number of groups is about 3-6.

3. Analytical maps is created.

4. The specific resistance of this information is calculated.

5. The possibility of landslides is calculated.

6. The impact of some factors on landslide growth is assessed.

7. Landslide potential is calculated.

Distribution maps of some factors of landslide occurrence are recreated on these materials. The Terrain brand is a triangular model of a temporary network (TIN). A temporary network of points there is distributed in relation to the terrain properties. This temporary sample shows the type of surface well.GRID in ArcGIS GIS is reproduced by recalculating the values of these points by the values of the permanent network.

At the beginning of VLS using the GIS toolkit ArcGIS is the creation of a few analytical maps. For example: a slope map, a watercourse map. The plane constructed on the TINmodel of the relief is depicted in the image of a polyhedron. In GIS, the ArcGIS map is built in several stages using the SpatialAnalyst module and the Hydrology tools.

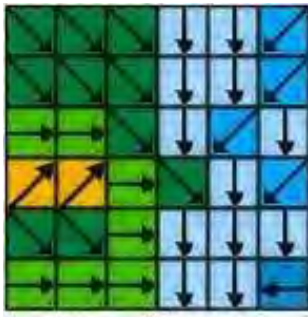

Flow direction

\begin{tabular}{|l|l|l|l|l|l|}
\hline 0 & 0 & 0 & 0 & 0 & 0 \\
\hline 0 & 1 & 1 & 2 & 2 & 0 \\
\hline 0 & 3 & 7 & 5 & 4 & 0 \\
\hline 0 & 0 & 0 & 20 & 0 & 1 \\
\hline 0 & 0 & 0 & 1 & 24 & 0 \\
\hline 0 & 2 & 4 & 7 & 35 & 2 \\
\hline
\end{tabular}

Flow accumulation

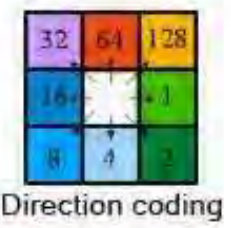

Fig. 5. Identification of total flow. 
Flow Direction in Figure 4 (taken from Kuzin AA's dissertation, "Geodesic support of zoning of territories according to the degree of hazard of landslide processes based on GIS technologies"), shows the distribution from one camera to another, and Flow Accumulation presents the number of cameras included in each camera.

Then the network of watercourses is distributed. According to the created grid of square chambers with a side length of 1 $\mathrm{km}$, the total number of lengths of watercourses trapped in each chamber is calculated. If no watercourse passes into the chamber, then the 0th value is assigned.

The formation of thematic maps of remoteness from reservoirs, settlements, trails, is possible through the means of the Distances group of the SpatialAnalyst module. The basis for the formation of rasters are vector, digitized from the map coverage, which find the location of these objects. The last map is recreated using a grid of squares with the specified side lengths. Artificial neural networks (ANNs) are a system of interconnected normal neurons.

The basis of this method is the concept of preparing a neural network for determining and detecting interconnections as part of indicators. In the basis of sample many objects will be provided. According to the prepared sample, the system gives the main conditions. The connection between incoming and outgoing materials is available during the development of the network.

In the example of landslide prediction, the circumstances that gave a description of the conditions for the selfdevelopment of the landslide process become the objects of the developing sample. With the help of neural networks, the detection of safe terrain based on landslide research is likely. The neural network establishes connections between landslides and gains the ability to recognize similar factors.

The most convenient for the study of dangerous areas is the kinoteodolite method. This method was used in the study of landslide processes in the Staropromyslovskiy district, Grozny. One of the observational objects was chosen from the Sunzhenskiy range from the northern slope to the south of the village of Podgorny in the Staropromyslovskiy district of the city of Grozny [12].

A landslide over the village of Podgorny, Staropromyslovskiy district, Grozny, belongs to the zone of the ancient potential landslide slope around the Sunzhenskiy range. The danger of a slope penetrating is explained by its geomorphological parameters, namely, a enough steepness, which varies from 10 to 20 degrees, and the presence of a covering of clay deposits, which are subject to drowning or other impacts, including man-made landslides.

On the slopes the ancient forms of erosion depicted by the flow of the valley are strongly expressed. In 2010-2011, there was an activation of landslides over the village, as a result of landslides 6 houses were destroyed, about 90 houses had the risk of deformation or complete destruction [13].

It should be noted that landslide activation in the Chechen Republic occurs annually in different areas, often accompanied by an increase in landslides and an emergence of new landslides in previously relatively stable areas. Thus, in the study in 2017, signs of a seasonal increase in landslides were found. With the resumption of growth and deepening of old cracks they were fixed because of the department's walls, as well as the emergence of new landslides on the slope.

Objects of monitoring in the expert area:

- meteorological parameters;

- $\quad$ seismic effect on the intensity degree;

Displacement of surface points at idle.

The experimental area of the automated monitoring system contained:

- automatic control terminal, equipped with video surveillance modules, control of strong seismic movements of the earth's crust and meteorological monitoring;

- software and hardware complex for monitoring processes automatically with built-in communication system and warning the population in case of an unfavorable forecast of the situation development.

The connection between the elements of the monitoring system was established via the Internet and MegaFon mobile communication

The module of meteorological monitoring and control of strong movements of the earth's crust was laid because of part PM-5 in Grozny on the territory of Staropromyslovskiy district. The video monitoring module was created directly on the territory of the village Podgorny. The video part monitoring was stationary, which was installed in the area of the sunken slope on the Sunzhenskiy range. The benchmark was marked, the upper part was painted white with a red frame to optimize observation in various conditions and in the dark.

All observations were reproduced on a computer screen by transferring images from video cameras installed on a slope.

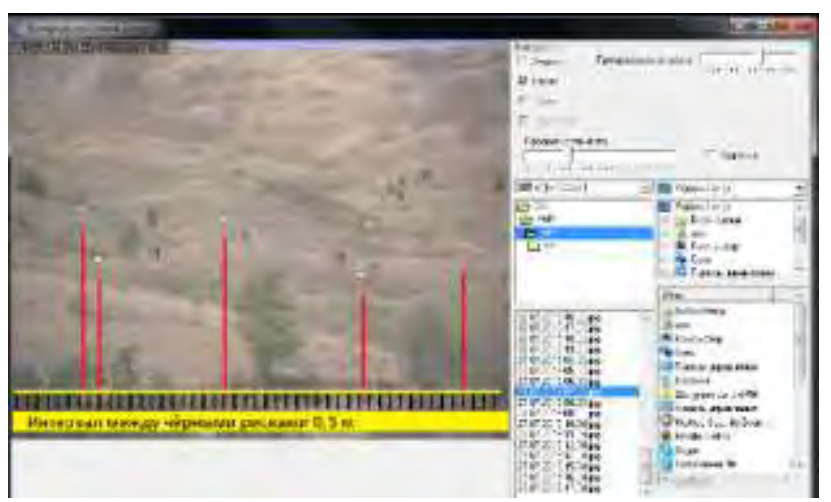

Fig. 6. Interface of video monitoring user.

Kinoteodolite is a type of theodolite, which is designed to record the trajectories of objects moving on the earth's surface and in the air. This method involves the traceability of the observed trajectory by measuring the angular displacements of the sight line to the object.

The parametric monitoring method and film-theodolite video monitoring can be used separately. However, it is their 
combination that gives a "synergistic" effect manifested in the timely detection of an active landslide, the early adoption of measures to protect the population and, ultimately, the reduction of material losses.

The independent use of the kinoteodolite method, of course, is possible, but rather belongs to the geological observations of the landslide massif. As a result of such observations, the accumulation of materials over several years is possible. It allows to describe the behavior of the landslide body in different meteorological and geophysical conditions.

The software allows to quickly track the threat indicators appearance.

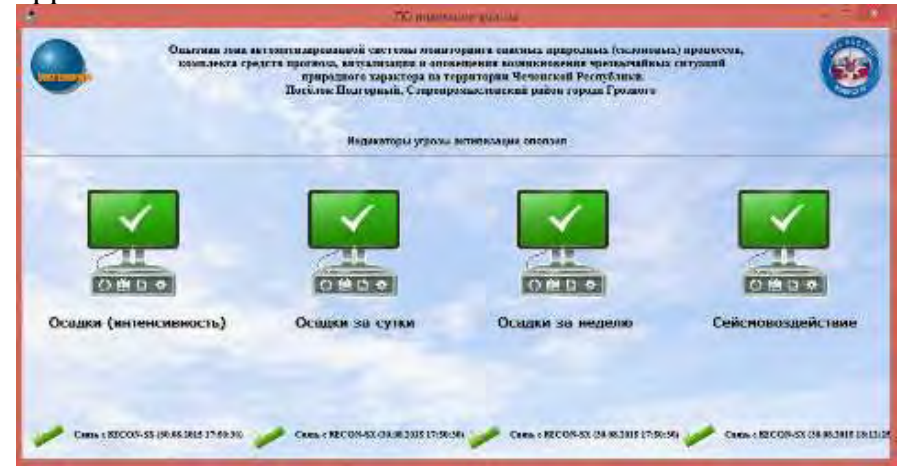

Fig. 7. Threat identifying.

Thus, the algorithm of automated monitoring system for hazardous natural (oblique) processes is implemented by a combination of parametric control and kinoteolytic motion control:

1. Continuous meteorological monitoring of landslide processes indicative parameters;

2. Control over the strong movements of the earth's crust by controlling seismic effects.

3. The threat indicator for Hang audio and video provisions changes and transmits information about hazardous meteorological and geophysical phenomena that are a precursor to the activation of landslides.

4. After receiving a signal about a dangerous development of events, measures to protect the population in a dangerous area can be taken.

5. If the shift in dynamics is not obvious, the predicted probability of heartbeats occurrence is calculated based on the predictions.

Here is an example of monitoring, using an automated system, conducted in August and the first half of September 2017:

- The precipitation recorded in August 2017 was 23 $\mathrm{mm}$.

- In the first half of September, precipitations amounted to $4 \mathrm{~mm}$.

- The system recorded a series of weak seismic influences in August and first half of September 2017. The intensity of these movements was 1 point on the MSK-64 scale.

Figure 9 shows the seismogram (it is a record of the module of the full acceleration vector) of the seismic impact. It was caused by an earthquake of magnitude 4.0 , which occurred on August 29, 2017 at 18.43 in $37 \mathrm{~km}$ south of Grozny. As can be seen from the seismogram, the maximum acceleration reached $0.29 \mathrm{~cm} / \mathrm{s}^{2}$, which corresponds to 1 MSK-64 scale point.

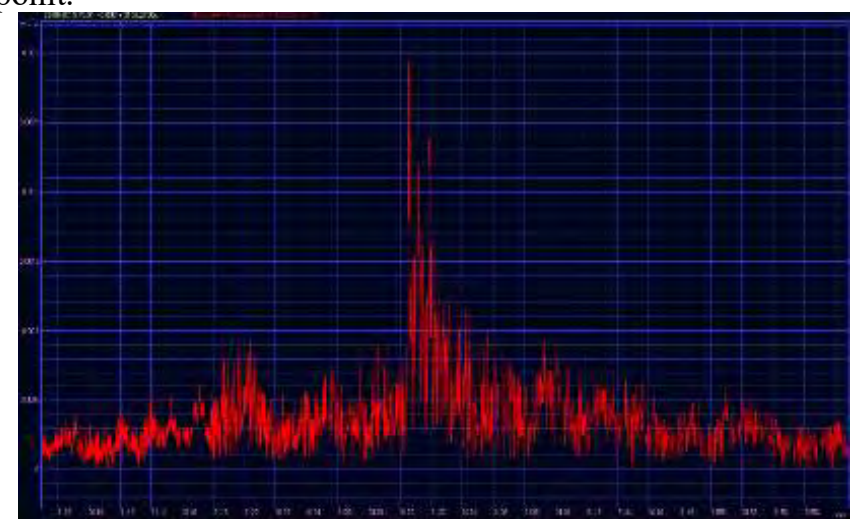

Fig. 8. Accelerogram 7.

Figure 9 shows the kinetic method of displacement control. It is a photo of the landslide site of September 13, 2017. The photo has red vizier risks corresponding to the initial position of the frames on July 23, 2017. There is a scale of displacements below. The direction from left to right in the photo corresponds to the direction from top to bottom of the slope. As can be seen, the surface benchmarks are not shifted to the right relative to the riser sights. Therefore, the slope is in a stable condition. Given the small amount of precipitation that fell during the period under review, this is quite an expected result.

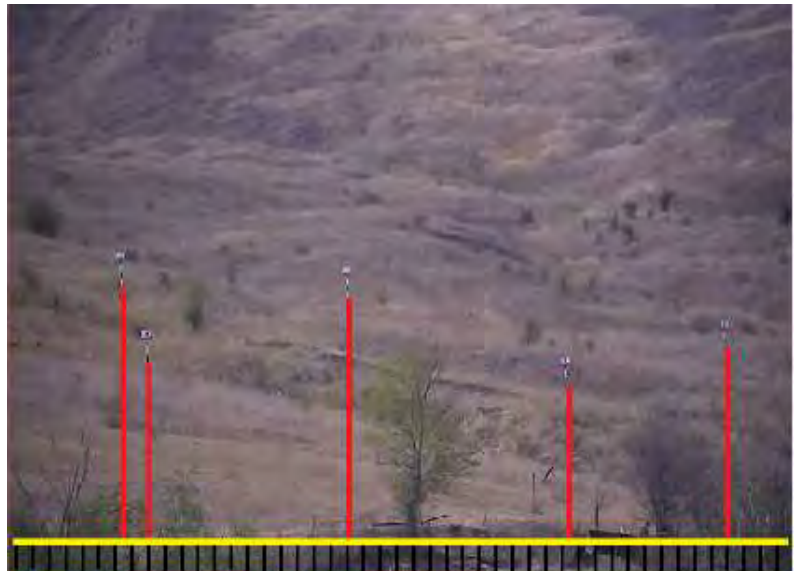

Интервал между чёрными рисками 0,5 м

Fig. 9. Picture of the landslide-prone slope in the software interface of the kinoteodolite method.

\section{CONCLUSION}

This article presents methods for predicting the occurrence and development of landslide processes.

Finally, using the kinoteodolite method it is possible to predict the unfavorable development of events and possible emergencies caused by a landslide.

The practical purpose is to create maps of areas with a high probability of landslide using these methods. It has become possible to develop an automated algorithm for regional zoning according to the degree of landslide hazard, which will include a complete and structured set of source data reflecting a 
combination of landslide formation factors and a technique based on GIS and neural networks.

The described methods should be applied in practice under the given terrain conditions. All this can help in building and disseminating approaches to creating cartographic bases that will create a basis for predicting other types of landslides and natural disasters on the earth's surface. In addition, it is advisable to study potentially dangerous landslide areas in the dynamics of the process of deformation of the earth's surface based on remote sensing data, including radar interferometry.

\section{References}

[1] A.A.Kuzin. Geodetic support of territories zoning according to the danger degree of landslide manifestations of processes based on the application of GIS technologies. Engineering sciences Cand. Diss. SaintPetersburg, 2014.

[2] D.A. Gur, G.G. Spevchenko, T.A Gura, D.T. Burdinov, "Basics of satellite navigation," Young scientist. 28 (132), pp. 64-70, 2016.

[3] T.V. Kravtsova, S.I. Kusova, D.A. Gura, "Systematization of data used in the operation of GIS for solving geo-ecological and cartographic tasks," Proceedings of the conference: Earth Sciences at the present stage. VI International Scientific and Practical Conference, pp. 128-130, 2012 .

[4] E.V. Pis'mennaya, A.A Tatarintseva, Domestic and foreign experience in organizing and managing an ecological network. Krasnoyarsk: Nauchnoinnovatsionnyy tsentr, pp.1270-1281, 2011.

[5] M.V. Maksimov, A.A. Tokareva, "Monitoring of high-rise building using modern technologies," Collection of articles on the results of scientific and technical conferences. Supplement to the Reports of Universities.Geodesy and aerial photography, vol. 7, pp. 119-124, 2014

[6] B.Yu. Erkushov, V.N Kononenko, "Impact of dynamic load on the landslide-hazardous road section in the area of Sochi," Bulletin of
Magnitogorsk State Technical University. G.I. Nosova, 4 (52), pp. 56-60. 2015

[7] A.M. Gumen, A.P. Pinchuk, I.G. Kissin, "Investigation of modern geodynamic processes of the Pripyat trough using the method of precision levelmetry of groundwater," Lggasfera-Lgasfera, 5, pp. 83-94, 1996.

[8] P.A. Lyashenko, V.V. Denisenko. Engineering Geology: Practicum. Krasnodar, 2016

[9] M.A. Pastukhov, A.S. Sukmanyuk, "Geological and hydrological characteristics of the valley of the Malaya Laba river," Scientific works of the Kuban State Technological University, vol. 10, pp. 60-69, 2016.

[10] G.I. Pensakov, G.G. Shevchenko, D.A. Gura, I.S. Gribkova, “Adaptation of remote sensing data for the rational use of land in the Russian Federation," Scientific works of the Kuban State Technological University, vol. 10, pp. 24-38, 2016.

[11] E.B. Klyushin, M.I. Kiselev, Sh. Mikhelev, V.D. Fel'dman. The engineering geodesy. Moscow: Akademiya, 2010

[12] E.V. Dmitriyeva, I.A. Sergeyev, S.I. Sergeyev, A.A. Stefanov, A.I. Tikhonov, "Monitoring and forecasting of landslide processes in the city of Grozny," Geology and Geophysics of the South of Russia, vol. 4, pp. $66-72,2015.1$

[13] K.N. Nosov, E.V. Zaporozhchenko. Assessment of the impact of hazardous geological processes on human settlements in Nozhai-Yurt, Shatoi, Itum-Kalinsky, Nadterechny, Vedensky, Grozny, Staropromyslovsky and Kurchaloy districts of the Chechen Republic, Pyatigorsk, 2011.

[14] I.G. Gayrabekov, "Accuracy Evaluation of determining the vertical displacements of the earth's surface by satellite methods," Materials of the international scientific-practical conference Innovative technologies in production, science and education in 2 volumes, vol. 1, pp. 142-150.

[15] I.G. Gayrabekov, V.V. Yakovlev, "Features of the geodetic substantiation design by a complex of satellite and optical-electronic measurements," University News. North-Caucasian Region. Technica Sciences Series. Annex to 16. pp.145-148, 2006. 